\title{
Research on Construction Technology and Management Measures of Urban Road Subgrade
}

\author{
Guoxiang Zhang* \\ Shentu Sapience Originality Engineering Technology Co., Ltd. E-mail: zhanggx@163.com
}

\begin{abstract}
With the rapid development of modern economy, the scale of cities is constantly expanding and the population is constantly growing. Strengthening urban construction has become one of the important work contents of socialist modernization in China. To build a modern city, road construction is the key work of urbanization. Subgrade is the most important construction link in urban road construction and the important foundation of road engineering. In this paper, combined with the specific conditions of urban roads, the construction technology and management measures of urban road subgrade are deeply explored, and perfect construction schemes and management measures are formulated to provide more reliable reference basis for promoting urban development and construction.
\end{abstract}

Keywords: Urban Roads; Roadbed; Construction Management; Measures

\section{Introduction}

Transportation is an important part of a city, and it is also the basic service function of a city. The rapid development of economy drives people's living standards to improve constantly, and at the same time puts forward higher requirements for urban service functions. Perfecting urban infrastructure and relieving traffic pressure have become the key requirements for the development and construction of modern cities. In the process of urban road subgrade construction, subgrade construction has a decisive impact on the quality and performance of urban roads, and is closely related to urban traffic environment and traffic service capacity. Therefore, the quality management of urban road subgrade construction is particularly important. Exploring the construction technology and publicity measures of urban road subgrade to improve the quality of urban road construction is a key issue in the process of urban road construction.

\section{Urban road subgrade construc- tion quality requirements}

Urban road subgrade construction quality has a direct impact on urban traffic safety. In the process of urban road subgrade construction, there are mainly the following requirements for road quality.

Firstly, the subgrade structure has high stability requirements. Only by ensuring the stable structural layout of the subgrade can the bearing capacity of the subgrade be effectively improved and the vehicle driving load be increased. Therefore, in the process of urban road construction, it is crucial to ensure the stability and quality of subgrade construction. Only by ensuring good overall structural stability of the subgrade can we effectively prevent the adverse effects of vehicle loads and natural factors on the subgrade, resulting in deformation and destruction of the pavement, and finally causing traffic accidents. 
Secondly, the subgrade strength and stability have higher requirements. The rapid development of urban economy has brought greater pressure to traffic, which requires subgrade to have good load capacity and strength, otherwise it will cause road surface settlement, which will not only affect road performance, but also lead to traffic accidents.

Thirdly, it has higher requirements for water temperature stability. Both surface water and groundwater will affect the subgrade strength, which will be seriously weakened under the impact of water flow for many years. Especially in winter construction, the difference of water temperature will make the subgrade freeze-thaw effect, causing frost heaving and frost boiling, which will weaken the subgrade strength and affect the construction quality of urban road subgrade. Therefore, it is necessary to ensure the stability of water temperature in road foundation construction, so as to ensure that the subgrade strength reaches the standard.

\section{Road subgrade construction technology points for attention}

\subsection{Subgrade earthwork excavation tech- nology}

In the process of urban road subgrade construction, earthwork excavation is one of the most critical technologies affecting the construction quality. In the process of earthwork excavation, the key point of construction technology is to make corresponding preparations before excavation. Only with adequate preparation can we ensure the smooth progress of subgrade earthwork excavation. The preparation of earthwork excavation technology mainly includes the following two aspects.

First of all, the surface debris in the subgrade construction area must be thoroughly cleaned to ensure that the area is clean and free of debris accumulation. At the same time, the excavation of drainage ditch and intercepting ditch must be done well to ensure the quality and safety of earthwork excavation.

Secondly, subgrade earthwork excavation is closely related to geological environment conditions. Therefore, before construction, it is necessary to conduct a comprehensive survey of the geological environment of the construction site, fully understand the geological environment, and rationally design and plan anti-seepage works according to the requirements of road subgrade construction, so as to preserve the construction quality of road subgrade engineering.

\subsection{Subgrade filling and compaction tech- nology}

Filling and compaction is the key environment and main construction technology of urban road subgrade construction, which has a vital impact on subgrade construction quality. In the construction of subgrade filling, the construction unit is required to adopt the soil and stone with qualified quality and meeting the requirements of engineering construction according to the relevant national standards. The constructor must strictly distinguish the upper layer types in the construction area and conduct sampling experiments, and scientifically and reasonably select the filling materials according to the experimental results. Materials with poor engineering mechanical properties are strictly prohibited. At the same time, in order to improve the construction quality, we must strictly control the material ratio, ensure that the filling material quality meets the relevant national standards and requirements of subgrade construction, effectively improve the quality of subgrade construction, and effectively optimize the subgrade performance.

In the process of subgrade construction, compaction is an essential and important link, and it is also one of the main steps of subgrade construction. For compaction construction, a large-tonnage road roller must be used to compact the subgrade filler. Compaction construction can not only effectively improve the subgrade strength and bearing capacity, but also accelerate the construction progress.

\subsection{Subgrade slope protection technology}

Slope protection of road subgrade plays an important role in ensuring construction safety. This is because in the process of subgrade construction, the stability and environment of soil structure and surrounding rock and soil will be damaged. If effective protective measures are not adopted, the subgrade will be eroded by external factors, which will affect the quality of road engineering and pose a serious threat to road traffic safety.

In the process of urban road subgrade construction, in order to avoid the erosion of subgrade slope caused by 
water, the slope must be effectively protected. When applying subgrade slope protection technology, we should pay attention to the following aspects.

First of all, we must fully understand the slope of the road side slope, and fully consider the flooding and surface runoff velocity. For example, the slope does not exceed 1:1, and there is no flooding on the ground, or the flooding time is short, and the surface runoff velocity does not exceed $0.6 \mathrm{~m} / \mathrm{s}$. In this case, the more appropriate slope protection technologies are grass irrigation, spraying and planting grass protection.

When the slope is weathered rock slope, with rocks on it or soil slope with high liquid limit, it is necessary to use galvanized iron wire fence and spray planting grass to protect the slope. For high liquid limit soil slope, a waterproof geomembrane should be added. In the process of subgrade construction, the geological conditions in different areas are different, such as the different development degree of rock joints, cracks and weathering, etc. Different protection technologies must be adopted to effectively protect the subgrade slopes under different conditions, so as to effectively ensure the safety and good quality performance of subgrade construction.

\subsection{Subgrade seepage control and drainage treatment}

In urban road subgrade construction, the importance of drainage treatment is self-evident, which has a vital impact on the quality and safety of subgrade construction. Good drainage treatment can effectively prevent runoff from infiltrating into subgrade, improve subgrade stability, and then strengthen road bearing quality and ensure normal running of vehicles. Therefore, it is very important to do a good job in prevention and drainage system construction in the process of subgrade construction. In the specific construction process, the following aspects are mainly achieved.

First of all, waterproof materials must be scientifically selected to ensure that the waterproof materials have good water stability, which can fully meet the requirements of slope protection construction and ensure the drainage effect of slope.

Secondly, in the construction process, according to the slope topography and the actual geological conditions, the drainage system should be set scientifically to effectively eliminate the surface water, and anti-seepage geotextiles should be used to cut off the surface water to prevent the surface water from infiltrating downward.

\section{Road subgrade construction management measures}

\subsection{Preparation before construction}

In the process of urban road subgrade construction, the construction sequence will also affect the subgrade construction quality. The first step of a standardized construction sequence is to make preparations before construction, and the construction provides everything it needs. To make preparations before construction, we can start from the following aspects.

First of all, it is necessary to conduct a comprehensive survey of the hydrogeological conditions in the subgrade construction area, scientifically design the construction methods and reasonably select the construction techniques according to the actual hydrogeological conditions.

Secondly, the buildings, underground pipelines and surrounding environment around the construction area should be strictly investigated, especially the soil quality. If it is soft soil, effective measures must be taken to treat the soft soil, so as to improve the integrity and bearing capacity of the soil layer and ensure the quality and performance of the subgrade. In view of the problem of laying underground pipelines, it is necessary to communicate with relevant departments to fully understand the specific laying conditions of underground pipelines, so as to provide reference for the formulation of construction schemes and avoid the adverse effects of subgrade construction on underground pipelines as far as possible.

Finally, in the process of subgrade construction, it is necessary to select construction machinery and equipment reasonably. When selecting construction machinery and equipment, the geological environment characteristics and construction technical requirements of urban road subgrade construction site should be fully considered, and various influencing factors should be comprehensively analyzed, so as to make the most appropriate choice. After determining the mechanical equipment needed for subgrade construction, the entry and exit time of mechanical equipment should be arranged reasonably according to the construction period and progress. In 
order to save costs, it is necessary to rent equipment reasonably, so as to waste funds.

In addition to the above points, in the preparation stage before construction, it is very important to design the construction drawings. Combined with the actual situation and relevant data information, the construction drawings should be designed reasonably and checked carefully whether there are errors in the drawings. This is an important condition to ensure the smooth progress and quality of urban road subgrade construction.

\subsection{Strengthening the quality control of sub- grade construction}

In the management of urban road subgrade construction, it is necessary to strengthen quality control and comprehensively implement management measures, so as to effectively ensure the construction quality and safety. Construction enterprises shall carry out construction work in accordance with the requirements of relevant standards and specifications for subgrade engineering construction and at the same time carefully complete self-inspection. During the construction, if the design scheme is found to be inconsistent with the actual project, it is necessary to stop the construction immediately and communicate with the design unit immediately. Construction will rework or continue according to feedback from design unit.

\subsection{Strictly control of the quality of con- struction materials}

The quality of construction materials is an important factor affecting the performance of subgrade. The construction units and supervision units must strictly control the construction materials to ensure the quality of construction materials is qualified. In the procurement process, raw materials with qualified quality and excellent properties should be selected in strict compliance with relevant national standards and specifications and engineering construction requirements. Besides, the quality of raw materials that enter the construction site should be inspected, and only when they conform to the requirements of the standard can they enter the construc- tion site. In the construction site, raw materials should be classified and stored, and corresponding protective measures should be taken to prevent the materials from deteriorating, so as not to affect the subgrade construction quality.

\section{Conclusion}

In urban road subgrade construction, construction technology and management measures play a decisive role in the construction quality of subgrade engineering. Scientific and reasonable selection and application of construction technology is an important measure to ensure the quality of subgrade construction and the overall stability and safety of urban road engineering; Good management measures are an important guarantee to improve the construction efficiency, save the construction cost and expand the social and economic benefits of urban road engineering. Therefore, it is necessary to constantly explore the construction technology and management methods of urban road subgrade engineering and innovate management measures, so as to contribute to improving the level of urban road construction and improving the development of infrastructure construction in China.

\section{References}

1. Zhou C. Analysis of rock-filled subgrade construction and its quality management in urban road engineering construction (in Chinese). Global Market 2019; (7): 338.

2. Zheng D, Lu S, Song X. On the key points of urban road subgrade filling quality management (in Chinese). Project Management 2019; (9): 66-68.

3. Deng R. Discussion on construction treatment technology and common diseases of road and bridge engineering (in Chinese). Real Estate Information of China 2019; (35): 45.

4. Yao Z. Research on construction technology of soft foundation reinforcement in municipal road construction (in Chinese). Global Market 2019; (28): 339.

5. Qi X. Discussion on road subgrade construction technology of municipal public works (in Chinese). Juanzong, 2019; 9(20): 313. 